\title{
Microstructural and chemical variation in silica-rich precipitates at the Hellisheiði geothermal power plant
}

\author{
D. B. Meier ${ }^{1, *}$, E. Gunnlaugsson ${ }^{2}$, I. Gunnarsson ${ }^{2}$, B. Jamtveit ${ }^{3}$, C. L. Peacock ${ }^{1}$ and L. G. Benning ${ }^{1,4}$ \\ 1 Cohen Geochemistry Group, School of Earth and Environment, University of Leeds, Leeds LS2 9JT, UK \\ 2 Reykjavik Energy, 110 Reykjavik, Iceland \\ 3 Physics of Geological Processes, Department of Geoscience, University of Oslo, 0316 Oslo, Norway \\ ${ }^{4}$ GFZ German Research Centre for Geosciences, Helmholz Centre Potsdam, Telegrafenberg, 14473 Potsdam, \\ Germany
}

[Received 4 May 2014; Accepted 3 October 2014; Associate Editor: T. Rinder]

\section{ABSTRACT}

Precipitation of amorphous silica $\left(\mathrm{SiO}_{2}\right)$ in geothermal power plants, although a common factor limiting the efficiency of geothermal energy production, is poorly understood and no universally applicable mitigation strategy to prevent or reduce precipitation is available. This is primarily due to the lack of understanding of the precipitation mechanism of amorphous silica in geothermal systems.

In the present study data are presented about microstructures and compositions of precipitates formed on scaling plates inserted at five different locations in the pipelines at the Hellisheiði power station (SW-Iceland). Precipitates on these plates formed over 6 to 8 weeks of immersion in hot (120 or $\left.60^{\circ} \mathrm{C}\right)$, fast-flowing and silica-supersaturated geothermal fluids $\left(\sim 800 \mathrm{ppm}\right.$ of $\left.\mathrm{SiO}_{2}\right)$. Although the composition of the precipitates is fairly homogeneous, with silica being the dominant component and Fe sulfides as a less common phase, the microstructures of the precipitates are highly variable and dependent on the location within the geothermal pipelines. The silica precipitates have grown through aggregation and precipitation of silica particles that precipitated homogeneously in the geothermal fluid. Five main factors were identified that may control the precipitation of silica: (1) temperature, (2) fluid composition, (3) fluid-flow regime, (4) distance along the flow path, and (5) immersion time.

On all scaling plates, a corrosion layer was found underlying the silica precipitates indicating that, once formed, the presence of a silica layer probably protects the steel pipe surface against further corrosion. Yet silica precipitates influence the flow of the geothermal fluids and therefore can limit the efficiency of geothermal power stations.

KeYwords: silica, precipitates, scaling, geothermal power, Iceland.

\section{Introduction}

IN geothermal power plants around the world the polymerization of monomeric silica and the formation and deposition of amorphous silica $\left(\mathrm{SiO}_{2}\right)$ precipitates on pipes and other fluidhandling systems (most often referred to as 'scaling') have been identified as the most common problems limiting the efficiency of

* E-mail: eedbm@leeds.ac.uk

DOI: 10.1180/minmag.2014.078.6.04 geothermal power stations (Gunnarsson and Arnórsson, 2003). Although precipitation of amorphous silica in natural geothermal settings has been studied extensively (e.g. Mountain et al., 2003; Tobler et al., 2008), the processes that occur at the water-fluid-handling equipment

This paper is published as part of a special issue in Mineralogical Magazine, Vol. 78(6), 2014 entitled 'Mineral-fluid interactions: scaling, surface reactivity and natural systems'. 
interfaces (e.g. scale formation on pipes) are not well understood. A wide range of approaches to mitigate amorphous silica-scale formation, such as $\mathrm{pH}$ control (e.g. Fleming and Crerar, 1982; Henley, 1983; Stapleton and Weres, 2011), dilution and acidification with steam condensate (Gunnarsson and Arnórsson, 2003); or the use of (in)organic inhibitors (e.g. Amjad and Zuhl, 2008; Gallup, 2002; Gallup and Barcelon, 2005; Harrar et al., 1982) have been applied in various geothermal power plants. However, due to the large variations in geothermal fluid conditions, no single method for adequately mitigating silica scaling exists (Mroczek et al., 2011). One of the limits to developing a universally applicable mitigation approach is the lack of a fundamental understanding of the pathways and mechanisms of precipitation of amorphous silica. This is partly due to the dearth of data on silica-scale microstructures and compositions. In the present study, the microstructures and compositional characteristics of silica-dominated precipitates that formed in the pipes of the Hellisheiði geothermal power station in SW-Iceland were investigated.

\section{Materials and methods}

Silica precipitation was monitored using stainless steel scaling plates $(5 \mathrm{~cm} \times 2.5 \mathrm{~cm})$ deployed at different points within the pipelines of the Hellisheiði geothermal power plant, but in all cases after the steam used for the production of electrical energy was separated (Fig. 1). The chemical composition and $\mathrm{pH}$ of the separated water at sampling point 1 is monitored at regular intervals by the power plant operators. The separated water is cooled and filtered before the $\mathrm{pH}$ is measured and sample aliquots are taken for various analyses. For details of sample preservation and sampling containers see Arnórsson et al. (2006). The cations were analysed by ion chromatography (IC) at Reykjavik Energy while the anions were analysed using inductively coupled plasma-mass spectrometry at the University of Iceland. The concentration of $\mathrm{H}_{2} \mathrm{~S}$ is measured by titration with mercury acetate using dithizone as an indicator (Arnórsson et al., 2006).

The plates were inserted into the path of the flowing geothermal fluid for 6 (plates 2, 3 and 4) or 8 weeks (plates 1 and 5). After removal from

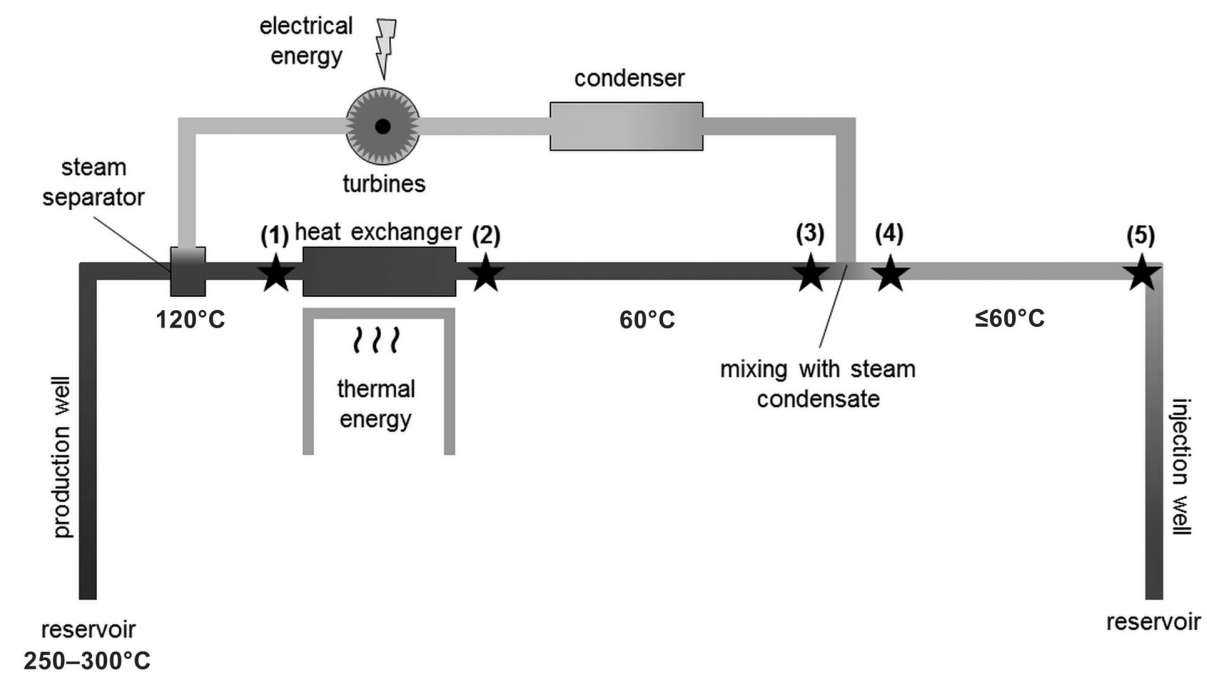

FIG. 1. System schematic of the Hellisheiði geothermal power station indicating the five points $(*)$ where the scaling plates were immersed. The geothermal fluid at depth, being at up to $300^{\circ} \mathrm{C}$, is flowing up through production wells. In the steam separator the pressure is released and the geothermal fluid boils, separating the steam (used for the production of electrical energy) from the fluid. The remaining geothermal fluid (also called separated water) is passed through a heat exchanger where it heats up cold groundwater to be used for space heating. Some tens of metres further along the flow path, the geothermal fluid is mixed with steam condensate to dilute it before reinjecting it some hundreds of metres further downstream (full details and schematics of the processes happening in geothermal power plants are available at http://www.or.is/vinnsluras). 
the separated water, the plates were first dried at room temperature on-site, and, after shipping to Leeds (UK), were dried again at $30^{\circ} \mathrm{C}$ for $24 \mathrm{~h}$ before further analysis.

Some precipitates were scraped off of one side of each plate using a plastic spatula and ground using an agate mortar and pestle. The powder was analysed by X-ray diffraction using a Bruker D8 diffractometer (XRD, $\mathrm{CuK} \alpha_{1} ; 5-90^{\circ} 2 \theta ; 0.01^{\%} \%$ step) and the patterns were evaluated using the EVA software (Bruker, Version 3.0). The other side of the plates was coated with $\sim 40 \mathrm{~nm}$ of gold and imaged using a field emission scanning electron microscope (FEG SEM, FEI Quanta 650 at $20 \mathrm{keV}$ ). Spot analyses and elemental mapping were performed using an energydispersive spectrometer (EDS) and the AZtec software (Oxford Instruments, Version 2.2).

\section{Results}

The separated water from which precipitation occurred is a dilute, low-ionic-strength fluid with a high concentration of dissolved $\mathrm{H}_{2} \mathrm{~S}$ and a $\mathrm{pH}$ varying between 9.1 and 9.4 (Table 1 ). Depending on which production well is used, the waters contain between 700 and $800 \mathrm{ppm}$

TABLE 1. Chemical composition of the separated water at sampling location 1 (Fig. 1; before the heat exchanger, $120^{\circ} \mathrm{C}$ ). The data represent average values of measurements between September 2012 and January $2014(n=4)$. The variations in $\mathrm{pH}$ and concentration are due to the use of different production wells, tapping different parts of the aquifer, at different points in time.

\begin{tabular}{ll}
$\begin{array}{l}\text { Separated water sample location } 1 \text { (before heat } \\
\text { exchanger) }\end{array}$ \\
\hline $\mathrm{pH}$ & $9.1-9.4$ \\
$\mathrm{Concentration}$ & $(\mathrm{mg} / \mathrm{kg})$ \\
$\mathrm{H}_{2} \mathrm{~S}$ & $25.2-30.4$ \\
$\mathrm{SiO}_{2}$ (total) & $694.9-787.2$ \\
$\mathrm{Na}$ & $194.6-209.4$ \\
$\mathrm{~K}$ & $26.1-36.6$ \\
$\mathrm{Ca}$ & $0.74-1.05$ \\
$\mathrm{Mg}$ & $<0.03$ \\
$\mathrm{Fe}$ & $<0.25$ \\
$\mathrm{Al}$ & $1.80-2.06$ \\
$\mathrm{Cl}$ & $161.6-193.6$ \\
$\mathrm{SO}_{4}$ & $16.2-54.6$ \\
$\mathrm{~F}$ & $1.2-1.6$ \\
\end{tabular}

$\mathrm{SiO}_{2}$ (Table 1). No data are currently available about solution compositions at the other sampling points.

After 6-8 weeks of immersion, all scaling plates showed visible signs of precipitation. Although the XRD analyses revealed silica as the dominant precipitate in all cases, the microstructures of the precipitates were highly variable (Fig. 2). Precipitation onto plate 1 occurred at $120^{\circ} \mathrm{C}$ due to its position directly before the heat exchanger (Fig. 1). The precipitates formed large (up to 1-2 $\mathrm{mm}$ ) fan-shaped structures pointing towards the direction of the flow (Figs 2, 3a). The fans were composed of silica particles $(\sim 1-20 \mu \mathrm{m}$ in diameter; Fig. 3f), while the rest of the plate was covered by individual silica spheres or idiomorphic Fe sulfides. The precipitates on plate 2 formed immediately after the heat exchanger (Fig. 1) at $60^{\circ} \mathrm{C}$. They formed wave-shaped structures, oriented parallel to the flow (Fig. 2), again consisting of larger, weakly aggregated silica spheres. These were overlying a film of smaller silica particles forming aggregates up to $50 \mu \mathrm{m}$ in diameter (Fig. $3 b$ ). Plate 3 was located immediately before the point at which the geothermal fluid is mixed with steam condensate fluid (Fig. 1), and was characterized by the smallest amount of silica precipitates (Figs 2, $3 c$ ). The precipitates on plate 4 consisted of individual or connected flakes of a dark grey precipitate (Figs 2, 3d), which consisted of very small $(<1 \mu \mathrm{m})$ angular Fe sulfide aggregates and $(0.1 \mu \mathrm{m})$ spherical silica particles (Fig. $3 d$; XRD results revealed mackinawite, greigite and pyrrhotite). The metal between the flakes was covered by spherical silica particles $(0.1-0.5 \mu \mathrm{m}$ in size) and idiomorphic, columnar sulfur crystals several $\mu \mathrm{m}$ long. Plate 5 was characterized by the largest amount of precipitate and was covered densely by grey ridges oriented perpendicular to the flow (Fig. 2). These ridges (Fig. 3e) were composed of individual, small silica spheres $(0.1-0.5 \mu \mathrm{m}$ in diameter) that were occasionally interspersed with larger, smooth silica particles (up to $10 \mu \mathrm{m}$ in diameter).

Along the rims of some plates, a clear morphological (Fig. 4a) and compositional (Fig. 5) layering was revealed. Underlying the silica precipitates (Figs 4b, 5) was a layer composed of fine-grained, often idiomorphic $\mathrm{Fe}$ sulfides (Fig. $4 c, 5$ ). In some areas even the corrosion of the stainless steel plates was observed in the form of rosette-shaped Fe oxides (Fig. 4d). Based on the shape of the mineral 


\section{plate 1}

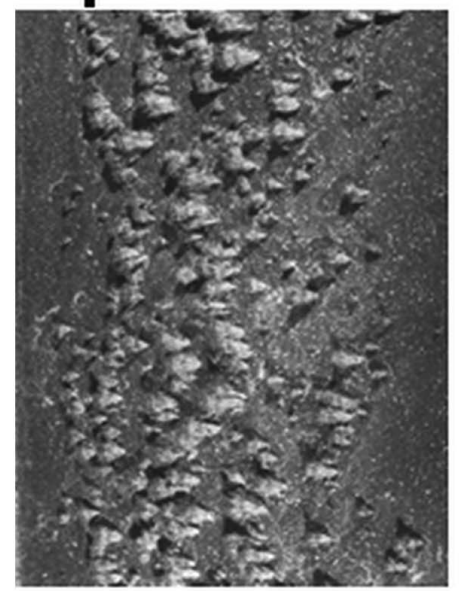

\section{plate 4}

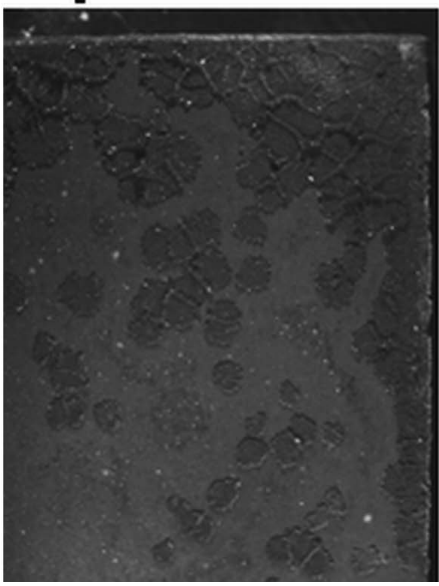

plate 2

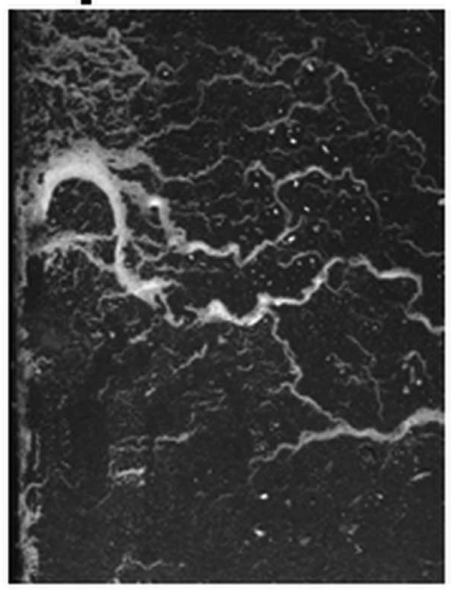

\section{plate 5}

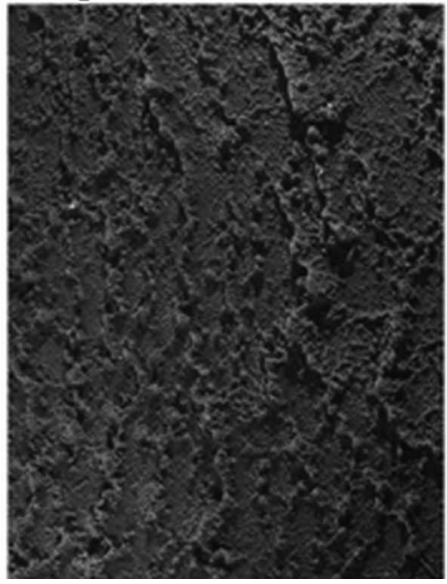

plate 3

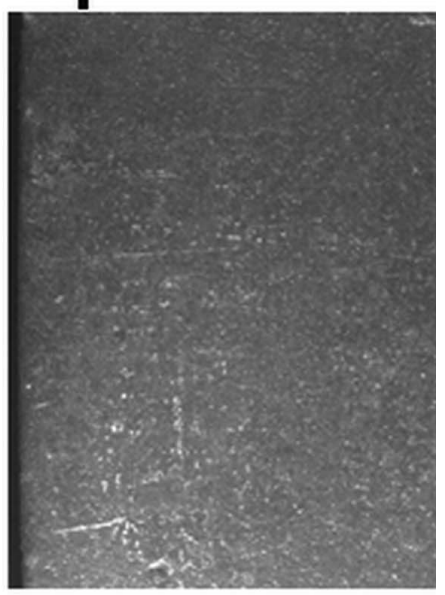

$\stackrel{\text { fluid flow }}{\longrightarrow}$

\section{$1 \mathrm{~cm}$}

FIG. 2. Photographs of the scaling plates after immersion in the geothermal fluid for 6 (plates 2, 3 and 4 ) and 8 weeks (plates 1 and 5), respectively. The precipitates on each plate show distinct microstructures from fan-shaped (1) to wave-like (2) to thin films (3) and to dark flakes (4) or even ridge-shaped (5).

phase, this was probably hematite. Due to the small amount of these Fe sulfides and Fe oxides on the plates, a definitive mineralogical identification or quantification was not feasible.

\section{Discussion}

The results from this study of precipitates formed on scaling plates immersed in the fast-flowing geothermal waters in the pipes of the Hellisheiði geothermal power station revealed that the microstructures and compositions of precipitates varied considerably along the flow path. Distinct microstructures that range from fan-shaped to wave-like to individual flakes or even ridgeshaped precipitates were observed. The dominant phases present on the scaling plates were amorphous silica, $\mathrm{Fe}$ sulfides and rarely $\mathrm{Fe}$ oxides. Silica was present as spherical nanoparticles which form by homogeneous nucleation 


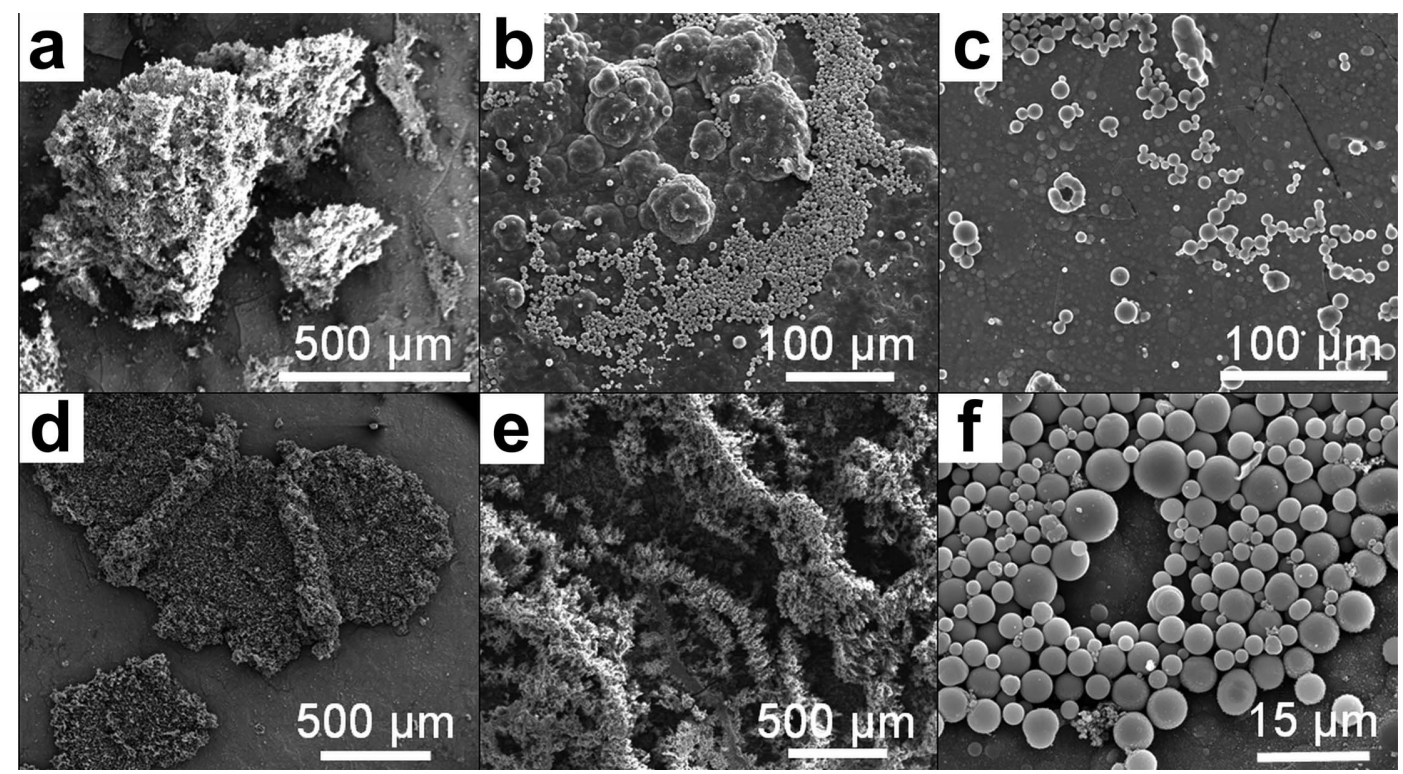

FIG. 3. FEG-SEM images showing the different microstructure of the precipitates on the scaling plates. The microstructures on plate $1(a)$, plate $2(b)$, plate $3(c)$ and plate $5(e)$ are formed by the aggregation of silica particles $(f)$.

On plate $4(d)$ the precipitates are dominated by Fe sulfides.

(Tobler et al., 2009, 2013) from the supersaturated geothermal fluids that contained $\sim 800 \mathrm{ppm}$ of silica. The data assembled indicate that once the particles that form in solution come into contact with the scaling plates (or the pipe surfaces) they are deposited. Monomeric silica will also polymerize continuously, cementing the particles together to form larger and larger clusters (Angcoy and Arnórsson, 2010). The iron phases ( $\mathrm{Fe}$ sulfides and $\mathrm{Fe}$ oxides) largely represent corrosion products. The Fe could be sourced either from the plates or pipes themselves or from the geothermal fluid and when combined with $\mathrm{H}_{2} \mathrm{~S}$ from the geothermal fluid would precipitate as Fe sulfides, and upon oxidation probably transform to $\mathrm{Fe}$ oxides.

The observed variations in composition and microstructures are the result of differences in physicochemical conditions in the power-plant pipelines. Although the data assembled so far cannot fully explain all our observations, five parameters have been identified that play a crucial role in controlling the precipitation regimes and modes of amorphous silica deposition on our scaling plates. These are:

(1) Variation in temperature: an increase in temperature results in greater rates of polymerization of monomeric silica and hence an increased rate of formation of amorphous silica nanoparticles (e.g. Alexander, 1954; Kitahara, 1960; Tobler et al., 2013). At higher temperatures this effect could be counterbalanced by the greater solubility of amorphous silica and the resulting decrease in supersaturation (Gunnarsson and Arnórsson, 2000; Makrides et al., 1980).

(2) Variation in fluid composition: the composition of the geothermal fluid is crucial for the composition of the phases formed on the scaling plates. The dominant phases on plate 4, for example, which formed immediately after the addition of steam condensate to the geothermal fluid (Fig. 1), were Fe sulfides. In this case, the precipitation of Fe sulfides was enhanced locally because of the mixing with steam condensate. The concentration of dissolved iron in the steam condensate is marginally greater than in the separated water (power-plant operators, pers. comm.). Therefore, when the Fe-rich steam condensate mixes with the $\mathrm{H}_{2} \mathrm{~S}$ from the geothermal fluid this may result in the very fast precipitation of $\mathrm{Fe}$ sulfides. The addition of condensate also decreased the concentration of silica and diluted the geothermal fluid. Lower supersaturation of silica combined with reduced ionic strength of the geothermal fluid results in slower precipitation of silica (Fleming, 1986; 


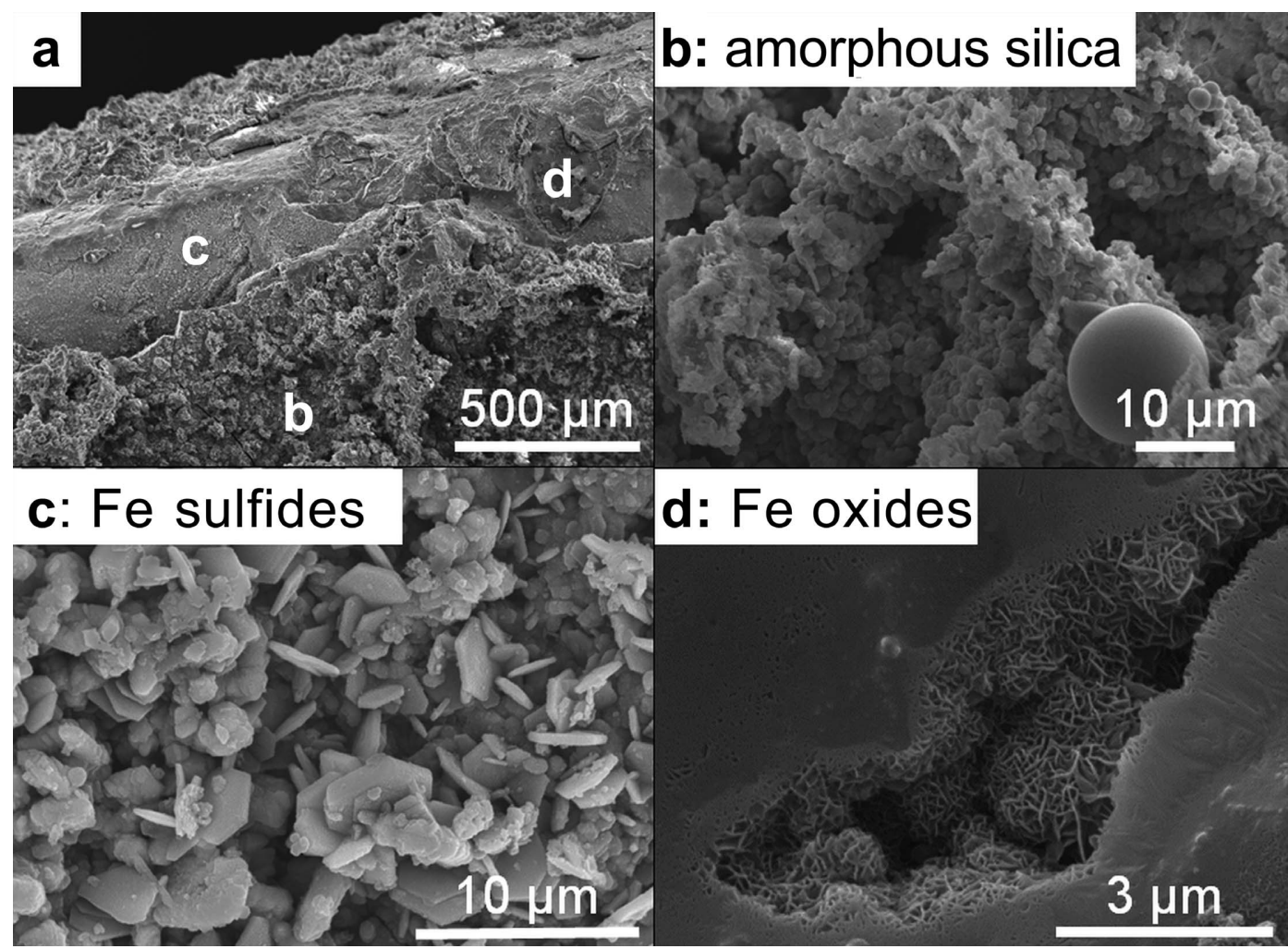

FIG. 4. (a) Different layers at the edge of plate 5 showing the top layer consisting of amorphous silica spheres, aggregated to form delicate structures $(b)$. The silica layer covers a layer of Fe sulfides $(c)$ probably a corrosion product of the scaling plate while underneath this layer, the metal of the scaling plate $(d)$ was oxidized to Fe oxides.

Icopini et al., 2005). This may, in part, explain the smaller amount of amorphous silica on plate 4 compared to all the other plates.

(3) Fluid-flow regime: fan-shaped structures like those on plate 1 have recently been modelled by Hawkins et al. (2014). The authors used fluid dynamic modelling approaches and simulated the surface growth processes in a geothermal pipeline in the presence of non-homogeneous and nonlaminar flow. Those authors found that the competition between advection and diffusion (Péclet number) and the turbulence characteristics (Reynolds number) define the exact geometry of the precipitates. The microstructures found on plate 1 (Figs 2, 3a) are matched by the modelling results, thus confirming that fluid flow does indeed play a dominant role. However, why this microstructure was only observed on plate 1 $\left(120^{\circ} \mathrm{C}\right.$, before the heat exchanger) is not yet clear and further time-resolved immersion experiments that are in progress hope to address this.
(4) Distance along the flow path: the precipitation of silica is affected by the distance between a spot where the physicochemical conditions in the power-plant pipelines change drastically and the location of the scaling plate. An example is the effect of cooling the geothermal fluid from 120 to $60^{\circ} \mathrm{C}$ in the heat exchanger: This temperature drop affects the rate of polymerization rate and it was shown by Tobler et al. (2013) that it may take up to $3 \mathrm{~h}$ to reach steady state again. Hence, the precipitation conditions where plate 2 is located are different from the conditions further downstream where plate 3 is located. Another example are the differences between plates 4 and 5. The addition of steam condensate enhances precipitation of Fe sulfides (see above) onto plate 4 . As plate 5 is located several hundred metres further downstream, the geothermal fluid at plate 5 had more time to react to the physicochemical disturbance and reequilibrate. Thus, at plate 5 , amorphous silica again becomes the primary precipitate. 


\section{VARIATION IN SILICA-RICH PRECIPITATES}
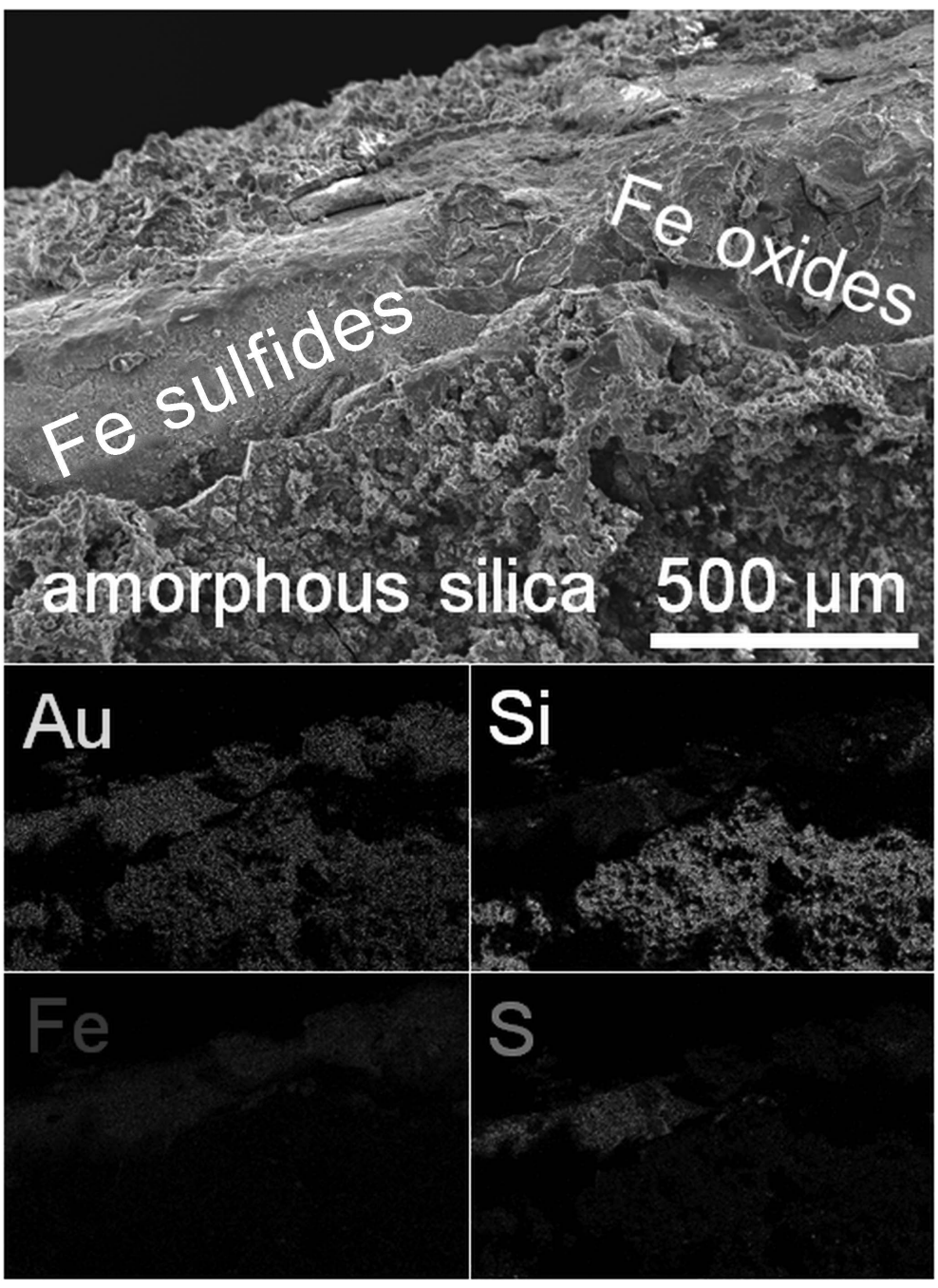

Fig. 5. Elemental maps of the layers on plate 5 described in Fig. 4 with the uppermost precipitation layer showing primarily Si which overlies the Fe sulfide layer (Fe and S maps) and the metal plate (Fe map). Dark areas on the $\mathrm{Au}$ map indicate areas where the topography of the sample resulted in a poor EDS signal. These areas will be dark in all elemental maps.

(5) Immersion time: the amount of time for which the scaling plates are immersed in the geothermal fluid will have an effect on the amount of material precipitated and probably on the microstructures formed. In the present study, only precipitation after 6 to 8 weeks was studied but precipitation has been monitored since commissioning of the Hellisheiði power station in 2006. The rates of precipitation are not known, however. In order to investigate precipitation and the evolution of microstructures as a function of time, additional time-resolved experiments are in progress.

In spite of detailed evaluation of the microstructures and compositions of the precipitates on the individual plates, the exact contributions of the individual factors mentioned above remain unclear.

All precipitates were made up of different layers (Figs 4, 5): (1) the stainless steel metal plate that in some cases was partly oxidized to $\mathrm{Fe}$ oxides; (2) the corrosion layer composed 
primarily of $\mathrm{Fe}$ sulfides; and (3) the main precipitation layer composed mainly of spherical amorphous silica and, in the case of plates 1 and $4, \mathrm{Fe}$ sulfides. The precipitation of amorphous silica (and Fe sulfides on plate 4), the corrosion of the plates and the related formation of Fe sulfides are probably concurrent processes both starting as soon as the plates are immersed in the geothermal fluids. The Fe sulfide corrosion layer was in most cases concealed under the silica precipitates, however, suggesting that before a protective amorphous silica layer could form, metal corrosion dominated. Once the precipitation layer became more continuous, further corrosion was passivated or at least slowed down by the amorphous silica (and Fe sulfides on plate 4) layer. Thus, the precipitation of amorphous silica does indeed limit the efficiency of geothermalpower production by reducing the flow of geothermal fluid through the system (Gunnarsson and Arnórsson, 2003) but, its deposition in thin, variable structured layers also helps to limit the corrosion of the steel pipes. To explore this passivation effect, a longer-term (12 months), time-resolved, scaling-plate exposure study is already underway.

\section{Conclusion}

The results presented here provide the first detailed description of silica-rich precipitates in pipes from the Hellisheiði power station. The microstructure and composition of the precipitates vary considerably depending on the ambient physicochemical conditions in the power-plant pipelines. However, exactly how and why particular physicochemical conditions lead to a variety of microstructures in the silica precipitates is still unclear. Nevertheless, this study presents important findings which, combined with fluidchemical data, information about fluid flow and longer-term scaling-plate immersion experiments, will allow us to derive the first comprehensive model for silica precipitation in geothermal systems and this information will potentially help to reduce silica scaling in geothermal power plants.

\section{Acknowledgements}

The authors acknowledge the help of the staff at the Hellisheiði power station, especially Einar Örn Thrastarson, for their support with emplacing and removing the scaling plates from the pipes.
The authors are also grateful to Richard Walshaw and Lesley Neve, University of Leeds, for their assistance with SEM and XRD analyses, respectively. Comments by several members of the Cohen Geochemistry group at Leeds, by Thomas Rinder (Guest Associate Editor) and three anonymous reviewers have helped to improve this manuscript. This research was made possible by a Marie Curie grant from the European Commission in the framework of the MINSC ITN (Initial Training Research network), Project number 290040.

\section{References}

Alexander, G. (1954) The polymerization of monosilicic acid. Journal of the American Chemical Society, 76, 2094-2096.

Amjad, Z. and Zuhl, R. (2008) An evaluation of silica scale control additives for industrial water systems. Paper No. 08368, CORROSION Conference \& Expo, NACE International, Houston, Texas, USA.

Angcoy, E. and Arnórsson, S. (2010) An experiment on monomeric and polymeric silica precipitation rates from supersaturated solutions. Proceedings of the World Geothermal Congress, Bali, Indonesia.

Arnórsson, S., Bjarnason, J.Ö., Giroud, N., Gunnarsson, I. and Stefánsson, A. (2006) Sampling and analysis of geothermal fluids. Geofluids, 6, 203-216.

Fleming, B.A. (1986) Kinetics of reaction between silicic acid and amorphous silica surfaces in $\mathrm{NaCl}$ solutions. Journal of Colloid and Interface Science, 110, 40-64.

Fleming, B. and Crerar, D. (1982) Silicic acid ionization and calculation of silica solubility at elevated temperature and $\mathrm{pH}$ application to geothermal fluid processing and reinjection. Geothermics, 11, 15-29.

Gallup, D.L. (2002) Investigations of organic inhibitors for silica scale control in geothermal brines. Geothermics, 31, 415-430.

Gallup, D.L. and Barcelon, E. (2005) Investigations of organic inhibitors for silica scale control from geothermal brines-II. Geothermics, 34, 756-771.

Gunnarsson, I. and Arnórsson, S. (2000) Amorphous silica solubility and the thermodynamic properties of $\mathrm{H}_{4} \mathrm{SiO}_{4}{ }^{\circ}$ in the range of $0^{\circ}$ to $350^{\circ} \mathrm{C}$ at $\mathrm{P}_{\text {sat }}$. Geochimica et Cosmochimica Acta, 64, 2295-2307.

Gunnarsson, I. and Arnórsson, S. (2003) Silica scaling: The main obstacle in efficient use of high-temperature geothermal fluids. International Geothermal Conference, Reykjavik, Iceland, 30-36.

Harrar, J., Locke, F., Otto, C.H., Jr., Lorensen, L., Monaco, S. and Frey, W. (1982) Field tests of organic additives for scale control at the Salton Sea geothermal field. Old SPE Journal, 22, 17-27.

Hawkins, C., Angheluta, L. and Jamtveit, B. (2014) 


\section{VARIATION IN SILICA-RICH PRECIPITATES}

Hydrodynamic shadowing effect during precipitation of dendrites in channel flow. Physical Review E, 89, 022402.

Henley, R. (1983) $\mathrm{pH}$ and silica scaling control in geothermal field development. Geothermics, 12, 307-321.

Icopini, G.A., Brantley, S.L. and Heaney, P.J. (2005) Kinetics of silica oligomerization and nanocolloid formation as a function of $\mathrm{pH}$ and ionic strength at $25^{\circ} \mathrm{C}$. Geochimica et Cosmochimica Acta, 69, $293-303$.

Kitahara, S. (1960) The polymerization of silicic acid obtained by the hydrothermal treatment of quartz and the solubility of amorphous silica. The Review of Physical Chememistry of Japan, 30, 131-137.

Makrides, A.C., Turner, M. and Slaughter, J. (1980) Condensation of silica from supersaturated silicic acid solutions. Journal of Colloid and Interface Science, 73, 345-367.

Mountain, B.W., Benning, L.G. and Boerema, J. (2003) Experimental studies on New Zealand hot spring sinters: Rates of growth and textural development. Canadian Journal of Earth Sciences, 40, 1643-1667.
Mroczek, E., Graham, D. and Bacon, L. (2011) Silica Deposition Experiments: Past Work and Future Research Directions. Proceedings International Workshop on Mineral Scaling in Geothermal Environments, Manila, The Philippines, pp. 51-58. Stapleton, M. and Weres, O. (2011) Recent Developments in Geothermal Scale Control. Proceedings International Workshop on Mineral Scaling in Geothermal Environments, Manila, The Philippines, pp. 69-76.

Tobler, D.J., Stefansson, A. and Benning, L.G. (2008) In-situ grown silica sinters in Icelandic geothermal areas. Geobiology, 6, 481-502.

Tobler, D.J., Shaw, S. and Benning, L.G. (2009) Quantification of initial steps of nucleation and growth of silica nanoparticles: An in-situ SAXS and DLS study. Geochimica et Cosmochimica Acta, 73, 5377-5393.

Tobler, D.J., Shaw, S. and Benning, L.G. (2013) The insitu and time resolved nucleation and growth of silica nanoparticles under simulated geothermal conditions. Geochimica et Cosmochimica Acta, 144, 156-168. 